\title{
Comparative Assessment of Two Strategies for Interpreting Tumor Markers in Ascitic Effusions
}

\author{
JAUME TRAPÉ ${ }^{1,2}$, FRANCESC SANT ${ }^{2,3}$, JESUS MONTESINOS ${ }^{4}$, ANNA ARNAU ${ }^{5}$, MARIA SALA ${ }^{1}$, \\ CRISTINA FIGOLS ${ }^{1}$, JOSEFINA FRANQUESA ${ }^{1}$, ENRIQUE ESTEVE-VALVERDE ${ }^{6}$, RAFEL PÉREZ $^{6}$, \\ JORDI ALIGUÉ 6 , SILVIA CATOT ${ }^{4}$, ESTHER CASADO ${ }^{4}$, MONTSERRAT DOMENECH $^{4}$, JORDI TRAPÉ-UBEDA ${ }^{7}$, \\ CARMEN BERGÓS ${ }^{8}$, FRANSCESC VIDA ${ }^{9}$, PAU SORT ${ }^{9}$, MARIONA BONET ${ }^{6}$, DOMINGO RUIZ $^{6}$, \\ CAROLINA GONZÁLEZ-FERNÁNDEZ ${ }^{1}$, JOSEP ORDEIG ${ }^{6}$ and RAFAEL MOLINA ${ }^{10}$ \\ ${ }^{1}$ Department of Laboratory Medicine, Althaia Xarxa Assistencial Universitària de Manresa, Manresa, Spain; \\ ${ }^{2}$ Facultat de Medicina, Universitat de Vic, Universitat Central de Catalunya, Vic, Spain; \\ ${ }^{3}$ Department of Pathology, Althaia Xarxa Assistencial Universitària de Manresa, Manresa, Spain; \\ ${ }^{4}$ Department of Oncology, Althaia Xarxa Assistencial Universitària de Manresa, Manresa, Spain; \\ ${ }^{5}$ Clinical Research Unit, Althaia Xarxa Assistencial Universitària de Manresa, Manresa, Spain; \\ ${ }^{6}$ Department of Internal Medicine Althaia Xarxa Assistencial Universitària de Manresa, Manresa, Spain; \\ ${ }^{7}$ Faculty of Pharmacy, Universitat de Barcelona, Barcelona, Spain; \\ ${ }^{8}$ Service of Gynecology Althaia Xarxa Assistencial Universitària de Manresa, Manresa, Spain; \\ ${ }^{9}$ Service of Gastroenterology, Althaia Xarxa Assistencial Universitària de Manresa, Manresa, Spain; \\ ${ }^{10}$ Department of Clinical Biochemistry, Hospital Clínic, Barcelona, Spain
}

\begin{abstract}
Background/Aim: There are two strategies for the interpretation of tumor markers (TM) in fluid effusions: $i)$ high cut-off and ii) fluid/serum ratio $(F / S)$ and low cut-off. The objective of this study is to compare these two strategies and to determine whether diagnostic accuracy improves by the identification of possible false positives using Adenosine deaminase (ADA), $C$ reactive protein $(C R P)$ and \% of polymorphonuclear cells (\%PN). Patients and Methods: We studied 157 ascitic fluids, 74 of which were malignant. ADA, $C R P$ and \%PN were determined in ascitic fluid, and Carcinoembryonic antigen (CEA), Cancer antigen 72-4 (CA72-4), Cancer antigen CA19-9 and Cancer antigen 15-3 (CA15-3) in both fluid and serum. Results: The strategy of high cut-off showed $59.5 \%$ sensitivity at 100\% specificity. The F/S strategy showed $75.7 \%$ sensitivity at $95.2 \%$ specificity. Subclassifying cases with ADA, CRP and \%PN
\end{abstract}

This article is freely accessible online.

Correspondence to: Jaume Trapé, Department of Laboratory Medicine, Althaia, Xarxa Assistencial Universitària de Manresa, F.P., Dr Joan Soler 1-3, 08243 Manresa, Catalonia, Spain. Tel: +34 938742112, e-mail: jtrape@althaia.cat

Key Words: Diagnosis, cancer, tumour markers, malignant ascites, differential diagnosis. negative showed $67.5 \%$ sensitivity at $100 \%$ specificity for high cut-off and for the F/S strategy was $81.7 \%$ sensitivity at $98.7 \%$ specificity. Conclusion: The strategy of $F / S$ with negative ADA, CRP and \%PN allow the best interpretation for TM in the ascitic fluid.

Ascites is the abnormal accumulation of fluid in the peritoneal cavity. It is mostly seen in patients with liver disease, pancreatic disease, tuberculous peritonitis, congestive heart failure, kidney disease, acquired immune deficiency syndrome and cancer (1). Cytology is the gold standard for confirming the presence of malignant cells in ascitic fluid, but its sensitivity only ranges between 50 and $70 \%$ (2). The main cause of this low sensitivity is the fact that a primary tumor may infiltrate the peritoneum but may not shed cells, with a negative result in the cytological analysis. In these cases, other invasive procedures, such as laparoscopy may be needed to confirm the presence of malignant cells.

The potential of tumor markers (TM) for improving the diagnosis of malignant pleural and peritoneal effusions has been mentioned by several authors but there are major discrepancies between the reports regarding their specificity and sensitivity, and also in terms of the cut-off values used (3-5): for Carcinoembryonic antigen (CEA) the range is 2$50 \mathrm{ng} / \mathrm{ml}$ and for Cancer antigen 19-9 (CA19-9) it is 14.5$200 \mathrm{ku} / \mathrm{l}$ (6-10). Their sensitivity ranges between $24 \%$ and $77 \%$ and their specificity from $82 \%$ to $100 \%$ (6-10). 
Establishing cut-off points is particularly difficult, because, among other reasons, different immunoassay kits obtain different concentrations in the same samples (11).

Another cause of the differences between studies is found in the types of benign diseases recorded. Tuberculosis and peritonitis may have high TM concentrations in peritoneal fluid, due to the inflammation of the mesothelial cells or nearby tissues $(12,13)$. Adenosine deaminase (ADA), Creactive protein (CRP) and granulocyte count are all used in the differential diagnosis of peritoneal inflammations, such as tuberculous effusions (14) and peritonitis (15-17).

Paramalignant effusions are another source of discrepancy. Although patients with these effusions have cancer, no neoplastic cells are present in the mesothelium; however, TM concentrations in serum may be high. So, tumour markers may be found in effusion fluids alongside other macromolecules, such as albumin, and they may be present in high concentrations in the serum of patients in the absence of neoplasia (18).

Taken together, to achieve high specificity using only TM values in effusions, high cut-off points have normally been used. However, in a previous study our group reported a strategy based on two criteria: i) low cut-off points and ii) the fluid/serum (F/S) ratio (19). Analyzing pleural, peritoneal and pericardial effusions and using a combination of CEA, cancer antigen 15-3 (CA15-3) and (CA19-9), we obtained a sensitivity of $76.2 \%$ and a specificity of $97 \%$. Similarly, subclassifying these effusions according to their ADA, CRP and $\%$ of polymorphonuclear cells (\%PN) value, we obtained a sensitivity of $80 \%$ and a specificity of $100 \%$ in patients with negative ADA, CRP and \% PN using the F/S ratio. In a recent study using this strategy we found similar sensitivities for CEA, CA15-3, CA19-9 and Cancer antigen 72-4 (CA724) in pleural effusion (20). This strategy is less accurate for tumor markers secreted by mesothelial cells, such as cancer antigen 125 (CA125) and cytokeratin 19 fragments (CYFRA 21-1) that are best interpreted with a single determination in fluid effusion $(21,22)$.

In the present study, we aimed to compare and assess the diagnostic accuracy of these two strategies: i) a cut-off point for each TM in fluid effusion to obtain maximum specificity, and ii) the $\mathrm{F} / \mathrm{S}$ in ascitic fluid in order to validate previous results. We also sought to determine whether the classification in groups according to ADA, CRP and \% PN might help improve diagnostic accuracy.

\section{Patients and Methods}

From January 2008 to December 2017, ascitic fluid and serum samples were collected from consecutive patients of all medical specialties at our center presenting a first episode of ascites. Patients with previously diagnosed liver cirrhosis were excluded. Diagnostic procedures were performed by ratters who were blind to the study data.
Table I. Etiology of the effusions included in the study.

\begin{tabular}{|c|c|c|c|}
\hline & ALL & $\begin{array}{c}\mathrm{ADA}<45 \mathrm{u} / \mathrm{l} \\
\text { and } \mathrm{CRP}<50 \mathrm{mg} / 1 \\
\text { and } \% \mathrm{PN}<90\end{array}$ & $\begin{array}{c}\mathrm{ADA}>45 \mathrm{u} / 1 \\
\text { or } \mathrm{CRP}>50 \mathrm{mg} / 1 \\
\text { or } \% \mathrm{PN}>90\end{array}$ \\
\hline Malignant & 74 & $59(79.7 \%)$ & $15(20.3 \%)$ \\
\hline Ovarian cancer/PSCP & 25 & $19(76.0 \%)$ & $6(24.0 \%)$ \\
\hline CUP & 14 & $13(92.9 \%)$ & $1(7.1 \%)$ \\
\hline Pancreas cancer & 8 & $6(75.0 \%)$ & $2(25.0 \%)$ \\
\hline Colon cancer & 8 & $5(62.5 \%)$ & $3(37.5 \%)$ \\
\hline Stomach cancer & 6 & $6(100 \%)$ & $0(0.0 \%)$ \\
\hline Cholangiocarcinoma & 3 & $3(100 \%)$ & $0(0.0 \%)$ \\
\hline Breast cancer & 2 & $2(100 \%)$ & $0(0.0 \%)$ \\
\hline Lymphoma & 2 & $0(0.0 \%)$ & $2(100 \%)$ \\
\hline Bladder cancer & 2 & $2(100 \%)$ & $0(0.0 \%)$ \\
\hline Endometrium cancer & 2 & $1(50.0 \%)$ & $1(50.0 \%)$ \\
\hline Hepatocarcinoma & 1 & $1(100 \%)$ & $0(0.0 \%)$ \\
\hline Mesothelioma & 1 & $1(100 \%)$ & $0(0.0 \%)$ \\
\hline Cirrhotic & 35 & $34(97.1 \%)$ & $1(2.9 \%)$ \\
\hline Paramalignant & 17 & $17(100 \%)$ & $0(0.0 \%)$ \\
\hline Cardiogenic & 12 & $10(91.7 \%)$ & $1(8.3 \%)$ \\
\hline Tuberculous & 4 & $1(25.0 \%)$ & $3(75.0 \%)$ \\
\hline No affiliate & 3 & $3(100 \%)$ & $0(0.0 \%)$ \\
\hline Mesenteritis & 3 & $3(100 \%)$ & $0(0.0 \%)$ \\
\hline Pancreatitis & 2 & $1(50.0 \%)$ & $1(50.0 \%)$ \\
\hline Viral & 2 & $2(100 \%)$ & $0(0.0 \%)$ \\
\hline Peritonitis & 1 & $0(100 \%)$ & $1(100 \%)$ \\
\hline \multicolumn{4}{|l|}{ Others: } \\
\hline $\begin{array}{l}\text { Post traumatic, uremic, } \\
\text { amyloidosis, nephrotic } \\
\text { syndrome. }\end{array}$ & 4 & $4(100 \%)$ & $0(0.0 \%)$ \\
\hline All & 157 & $135(86 \%)$ & $22(14 \%)$ \\
\hline
\end{tabular}

ADA: Adenosine deaminase; CRP: C reactive protein; \% PN: \% polymorphonuclear cells; PPSC: papillary peritoneal serous carcinoma; CUP: cancer of unknown primary.

The reference method used was pathological confirmation of cancer in serous effusions or a definitive diagnosis within three months off the determination of TM. Malignant ascites was defined as the presence of neoplastic cells detected by cytology, biopsy or autopsy. Paramalignant effusions were defined as effusions in which none of the methods described above detected neoplastic cells in patients diagnosed with cancer.

The following tests were performed in fluid and/or serum in order to identify benign effusions: protein (biuret method, albumin (bromochresol purple), lactate dehydrogenase (LDH) (lactate to pyruvate), rheumatoid factor in LX-20 autoanalyzer (Beckman Coulter, Madrid, Spain) N-terminal probrain natriuretic peptide (NtProBNP) in Cobas 601 analyzer (Roche Diagnostics, Barcelona, Spain), microbiological cultures, and (if required) antinuclear antibodies immunofluorescence in Hep 2 cells (Innova, Barcelona, Spain), anti-cyclic citrullinated peptide Unicap 250 (Thermofisher, Barcelona, Spain), thyrotropin, in DxI 800 analyzer (Beckman Couter), and serological tests for viruses (Vidas Biomerieux, Madrid, Spain), bacteria and fungi, among others.

Effusion fluid and serum samples were obtained and analyzed on the same day. CEA, CA15-3, CA 72-4 and CA19-9 were assessed using an electrochemiluminescence method on a Cobas 601 


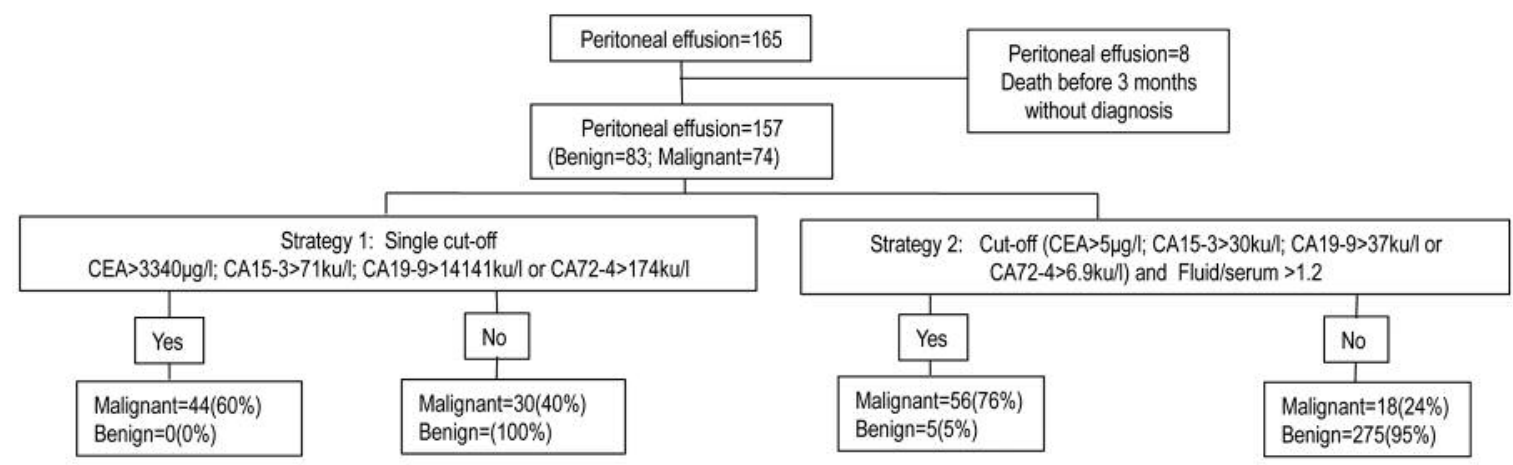

B

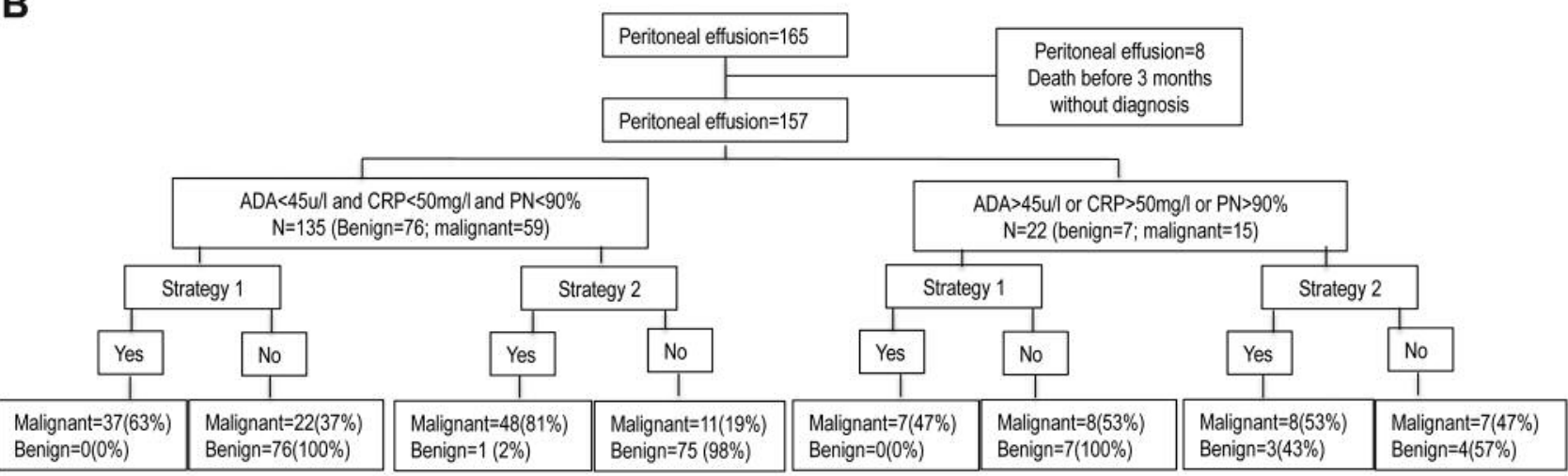

Figure 1. Flow chart of study. A. Flow chart for all group. B. Flow chart subclassifying according to adenosine deaminase (ADA), C reactive protein $(C R P)$ and \% polymorphonuclear cells (\%PN). CA15-3: cancer antigen 15-3; CA19-9: cancer antigen 19-9; CA72-4: cancer antigen 72-4. CEA: carcinoembryonic antigen; F/S: fluid serum ratio.

analyzer (Roche Diagnostics). The mean analytical variations expressed as the between-assay coefficient of variation were: $5 \%$ for CEA at a concentration of $5 \mu \mathrm{g} / 1,3 \%$ for CA15-3 at a concentration of $32 \mathrm{ku} / 1,4.2 \%$ for CA72- 4 at a concentration of 8.3 $\mathrm{ku} / \mathrm{l}$ and $4.5 \%$ for CA19-9 at a concentration of $29 \mathrm{ku} / \mathrm{l}$, There were no changes in the two techniques used throughout the study period. In the first, using a single measurement in ascitic fluid, we determined the cut-off for each TM at a specificity of $100 \%$ with the ROC curve. For the second approach, simultaneous measurements were made in fluid and serum, while effusions were deemed malignant when CEA, CA15-3, CA72-4 or CA19-9 in fluids were above the upper reference limit (URL) and the F/S ratio was above 1.2. TM in serum were measured only in patients with higher TM values in the effusion fluid compared to the URL in the serum ( $5 \mathrm{mg} / \mathrm{l}$ for CEA; $30 \mathrm{ku} / \mathrm{l}$ for CA15-3; $6.9 \mathrm{ku} / \mathrm{l} \mathrm{for} \mathrm{CA72-4,}$ and $37 \mathrm{ku} / \mathrm{l}$ for CA19-9).

The criteria used to indicate a possible false positive effusion (i.e., peritonitis, inflammation, or a tuberculous effusion) were $\% \mathrm{PN}>90, \mathrm{CRP}>50 \mathrm{mg} / 1$ or ADA $>45 \mathrm{u} / 1(19,20)$. The use of biomarkers ADA, CRP and \%PN identified two groups of effusions: i) group $\mathrm{A}$, with effusions containing all biomarkers under the cutoff point, and ii) group B, with effusions containing at least one positive biomarker. ADA (EC3.5.4.4) (ITC Diagnostics, Barcelona, Spain) and CRP (Tina-quant CRP latex, Roche Diagnostics) were assessed using an LX-20 autoanalyzer (Beckman Coulter).
Leukocyte count was determined using a Neubauer chamber and May-Grünwald-Giemsa stain. The analytical variation expressed as the between-assay coefficient of variation was $7.4 \%$ for ADA and $2.3 \%$ for CRP at concentrations of $10.3 \mathrm{u} / 1$ and $76.6 \mathrm{mg} / \mathrm{l}$ respectively. The Papanicolaou stain in Leica Autostainer XL (Leica, Barcelona, Spain) was used for cytology staining. This study was approved by the Ethical committee of the Unió Catalana d'Hospitals ( $\left.{ }^{\circ} 12 / 05\right)$.

Statistical analysis. ROC analysis was used to establish cut-off points for each TM at a specificity of $100 \%$. Sensitivity, specificity, negative predictive values (NPV), positive predictive values (PPV), likelihood ratio negative (LHR-) and likelihood ratio positive (LHR+), were all calculated for each TM and for all TMs combined. All statistical analyses were conducted using IBM $^{\circledR}$ SPSS $^{\circledR}$ Statistics for Windows v.20 (IBM Corporation, Armonk, NY, USA) and Stata ${ }^{\circledR}$ v.10 (StataCorp LP, College Station, TX, USA).

\section{Results}

One hundred and fifty-seven consecutive peritoneal effusions were included, from 84 women and 73 men with age ranging from 35 to 96 years (mean=67.7; $\mathrm{SD}=13.4)$. Of the effusions evaluated, $83(52.9 \%)$ had a benign etiology and $74(47.1 \%)$ 
in vivo $34: 715-722(2020)$

Table II. Diagnostic accuracy of tumor markers in all effusions (157).

\begin{tabular}{|c|c|c|c|c|c|c|c|c|c|c|}
\hline & \multicolumn{5}{|c|}{ Single cut-off ${ }^{\dagger}$} & \multicolumn{5}{|c|}{ Ratio $\mathrm{F} / \mathrm{S}^{\ddagger}$} \\
\hline & Sens & NPV & Spe & PPV & Acc & Sen & NPV & Spe & PPV & Acc \\
\hline CEA & 9.5 & 55.3 & 100.0 & 100.0 & 57.3 & 40.5 & 65.1 & 98.8 & 96.8 & 71.3 \\
\hline CA15-3 & 36.2 & 63.8 & 100.0 & 100.0 & 70.1 & 36.5 & 63.8 & 100.0 & 100.0 & 70.1 \\
\hline CA72-4 & 37.8 & 64.3 & 100.0 & 100.0 & 70.7 & 58.1 & 72.8 & 100.0 & 100.0 & 80.2 \\
\hline CA19-9 & 9.5 & 55.3 & 100.0 & 100.0 & 57.3 & 45.9 & 66.4 & 95.2 & 89.5 & 72.0 \\
\hline $\mathrm{CEA}+\mathrm{CA} 15-3+\mathrm{CA} 72-4$ & 59.5 & 73.5 & 100.0 & 100.0 & 80.9 & 74.3 & 81.2 & 98.8 & 98.2 & 87.3 \\
\hline All TM & 59.5 & 73.5 & 100.0 & 100.0 & 80.9 & 77.0 & 82.3 & 95.2 & 93.4 & 86.8 \\
\hline Cytology & 39.2 & 64.8 & 100.0 & 100.0 & 71.3 & 39.2 & 64.8 & 100.0 & 100.0 & 71.3 \\
\hline Cyto+CEA+CA15-3+CA72-4 & 68.9 & 78.3 & 100.0 & 100.0 & 85.3 & 79.7 & 84.5 & 98.8 & 98.3 & 89.8 \\
\hline \multirow[t]{2}{*}{ Cytology+TM } & 68.9 & 78.3 & 100.0 & 100.0 & 85.3 & 82.4 & 84.7 & 95.2 & 93.8 & 89.2 \\
\hline & \multicolumn{10}{|c|}{ Group A: Effusions with ADA<45 u/l; CRP<50 mg/l and \%PN <90 (n=135) } \\
\hline CEA & 11.9 & 59.4 & 100.0 & 100.0 & 61.5 & 47.5 & 71.0 & 100.0 & 100.0 & 77.0 \\
\hline CA15-3 & 35.6 & 66.7 & 100.0 & 100.0 & 71.8 & 40.7 & 68.5 & 100.0 & 100.0 & 74.1 \\
\hline CA72-4 & 43.7 & 69.7 & 100.0 & 100.0 & 75.6 & 63.7 & 78.4 & 100.0 & 100.0 & 84.4 \\
\hline CA19-9 & 10.2 & 58.9 & 100.0 & 100.0 & 60.7 & 54.2 & 73.5 & 98.7 & 97.0 & 79.3 \\
\hline $\mathrm{CEA}+\mathrm{CA} 15-3+\mathrm{CA} 72-4$ & 62.7 & 77.6 & 100.0 & 100.0 & 83.7 & 79.7 & 86.4 & 100.0 & 100.0 & 91.1 \\
\hline All TM & 62.7 & 77.6 & 100.0 & 100.0 & 83.7 & 83.1 & 88.2 & 98.7 & 98.0 & 91.9 \\
\hline Cytology & 44.1 & 69.7 & 100.0 & 100.0 & 75.6 & 44.1 & 69.7 & 100.0 & 100.0 & 75.6 \\
\hline Cyto+CEA+CA15-3+CA72-4 & 72.9 & 82.6 & 100.0 & 100.0 & 88.1 & 83.1 & 88.4 & 100.0 & 100.0 & 92.6 \\
\hline \multirow[t]{2}{*}{ Cytology+TM } & 72.9 & 82.6 & 100.0 & 100.0 & 88.1 & 86.4 & 90.4 & 98.7 & 98.1 & 93.6 \\
\hline & \multicolumn{10}{|c|}{ Group B: Effusions with ADA>45 u/l; CRP>50 mg/l and/or \%PN >90 (n=22) } \\
\hline CEA & 0.0 & 31.8 & - & - & 31.8 & 13.3 & 66.7 & 85.7 & 66.7 & 36.4 \\
\hline CA15-3 & 40 & 43.8 & 100.0 & 100.0 & 59.1 & 20.0 & 36.8 & 100.0 & 100.0 & 45.5 \\
\hline CA72-4 & 13.3 & 35.0 & 100.0 & 100.0 & 40.9 & 33.3 & 41.2 & 100.0 & 100.0 & 54.6 \\
\hline CA19-9 & 6.7 & 33.3 & 100.0 & 100.0 & 36.4 & 13.3 & 23.7 & 57.1 & 40.0 & 18.7 \\
\hline $\mathrm{CEA}+\mathrm{CA} 15-3+\mathrm{CA} 72-4$ & 46.7 & 46.7 & 100.0 & 100.0 & 63.6 & 53.3 & 46.2 & 87.5 & 88.9 & 63.6 \\
\hline All TM & 46.7 & 46.7 & 100.0 & 100.0 & 63.6 & 53.3 & 36.4 & 57.1 & 72.7 & 50.0 \\
\hline Cytology & 20.0 & 36.8 & 100.0 & 100.0 & 45.5 & 20.0 & 36.8 & 100.0 & 100.0 & 45.5 \\
\hline Cyto+CEA+CA15-3+CA72-4 & 53.3 & 50.0 & 100.0 & 100.0 & 68.3 & 66.7 & 54.5 & 87.5 & 90.9 & 73.7 \\
\hline Cytology+TM & 53.3 & 50.0 & 100.0 & 100.0 & 68.3 & 66.7 & 44,4 & 57.1 & 76.9 & 63.6 \\
\hline
\end{tabular}

Sen: Sensibility; Esp: specificity; NPV: negative predictive value; PPV: positive predictive value; Acc: accuracy; \%PN: \%polymorphonuclear cells; CEA: carcinoembryonic antigen CA15-3: cancer antigen 15-3; CA19-9: cancer antigen 19-9; CA72-4: cancer antigen 72-4. †CEA 3340 $\mu \mathrm{g} / \mathrm{l}$; CA15-3 71 ku/l; CA72-4 $174 \mathrm{ku} / \mathrm{l}$; CA19-9 $14141 \mathrm{ku} / \mathrm{l} .{ }^{\ddagger} \mathrm{F} / \mathrm{S}>1: 2$ and at least one of these CEA $>5 \mu \mathrm{g} / \mathrm{l}, \mathrm{CA} 15-3>30 \mathrm{ku} / 1, \mathrm{CA} 72-4>6.9 \mathrm{ku} / 1$ and CA19-9>37 ku/l.

were malignant (Table I). The staging of tumors involved in malignant ascites were: i) 18 stage IIIC ovarian cancers, ii) 7 stage IV ovarian cancers, iii) 48 stage IV peritoneal mesotheliomas and iv) one stage IIIA. The effusions were assigned to one of two groups: i) group A, with $\mathrm{ADA}<45 \mathrm{u} / 1$, $\mathrm{CRP}<50 \mathrm{mg} / 1$ and $\% \mathrm{PN}<90 \%$, and ii) group $\mathrm{B}$, with at least one of the following: ADA $>45 \mathrm{u} / 1, \mathrm{CRP}>50 \mathrm{mg} / \mathrm{l}$ and $\%$ PN $>90 \%$ (Table I). Figure 1 shows the flow charts for this study.

The cut-offs with a specificity of $100 \%$ obtained using the ROC curve method, with a single measurement in peritoneal effusions were: $71 \mathrm{ku} / \mathrm{l}, 3340 \mu \mathrm{g} / \mathrm{l}, 14141 \mathrm{ku} / \mathrm{l}$ and $174 \mathrm{ku} / \mathrm{l}$ for CA15-3, CEA, CA19-9 and CA72-4, respectively. Sensitivity and negative predictive value (NPV) for effusions with at least one TM above the cut-off were: $59.5 \%$ and $75.3 \%$ (Table II), respectively, and in patients with negative cytology (Table III), the sensitivity was $48.9 \%$ and NPV
$73.8 \%$. Considering only group A patients, the sensitivity was $62.7 \%$ for all patients and $51.5 \%$ in patients with negative cytology.

The alternative approach (i.e., at least one TM above the URL in peritoneal effusion and an F/S ratio>1.2) showed results for sensitivity, specificity, NPV and PPV of $75.7 \%$, $95,2 \%, 81.4 \%$ and $93.3 \%$, respectively for the whole group, and $68.9 \%, 95.2 \%, 84.9 \%$ and $84.9 \%$, respectively, in patients with negative cytology (Tables II and III). In group A, the specificity reached $98.7 \%$ and the sensitivity was $81.4 \%$ for all patients and $72.7 \%$ in patients with negative cytology (Tables II and III). In group A only CA19-9 showed a false positive result. The sensitivities of CEA, CA15-3 and CA72-4 were similar to the figures obtained when using four TMs, but the specificity was $100 \%$ at a sensitivity of $79.7 \%$ for all patients and at a sensitivity of $69.7 \%$ in the negative cytology group. 
Table III. Diagnostic accuracy of tumor markers in effusion with negative cytology ( $n=128)$.

\begin{tabular}{|c|c|c|c|c|c|c|c|c|c|c|}
\hline & \multicolumn{5}{|c|}{ Single cut-off ${ }^{\dagger}$} & \multicolumn{5}{|c|}{ Ratio F/S $\ddagger$} \\
\hline & Sens & NPV & Spe & PPV & Acc & Sen & NPV & Spe & PPV & Acc \\
\hline CEA & 15.6 & 68.6 & 100.0 & 100.0 & 70.3 & 31.1 & 72.6 & 98.8 & 93.3 & 75.0 \\
\hline CA15-3 & 24.4 & 70.9 & 100.0 & 100.0 & 73.4 & 28.9 & 72.2 & 100.0 & 84.0 & 75.0 \\
\hline CA72-4 & 28.9 & 72.2 & 100.0 & 100.0 & 75.0 & 46.7 & 77.6 & 100.0 & 100.0 & 81.2 \\
\hline CA19-9 & 4.4 & 65.9 & 100.0 & 100.0 & 66.4 & 37.8 & 73.8 & 95.2 & 81.0 & 75.0 \\
\hline CEA+CA15-3 +CA72-4 & 48.9 & 78.3 & 100.0 & 100.0 & 82.0 & 66.7 & 84.5 & 98.8 & 96.8 & 87.5 \\
\hline \multirow[t]{2}{*}{ All TM } & 48.9 & 78.3 & 100.0 & 100.0 & 82.0 & 68.9 & 84.9 & 95.2 & 84.9 & 85.9 \\
\hline & \multicolumn{10}{|c|}{ Group A (n=109) Effusions with ADA<45 u/l; CRP<50 mg/l and \%PN <90 } \\
\hline CEA & 21.2 & 74.5 & 100.0 & 100.0 & 76.1 & 39.4 & 79.2 & 100.0 & 100.0 & 81.6 \\
\hline CA15-3 & 21.2 & 74.5 & 100.0 & 100.0 & 76.1 & 33.3 & 77.6 & 100.0 & 100.0 & 79.8 \\
\hline CA72-4 & 36.4 & 78.3 & 100.0 & 100.0 & 80.7 & 51.5 & 82.6 & 100.0 & 100.0 & 82.3 \\
\hline CA19-9 & 6.1 & 71.0 & 100.0 & 100.0 & 71.6 & 48.5 & 81.5 & 98.7 & 94.1 & 83.5 \\
\hline $\mathrm{CEA}+\mathrm{CA} 15-3$ +CA72-4 & 51.5 & 82.6 & 100.0 & 100.0 & 85.5 & 69.7 & 88.4 & 100.0 & 100.0 & 90.8 \\
\hline \multirow[t]{2}{*}{ All TM } & 51.5 & 82.6 & 100.0 & 100.0 & 85.5 & 72.7 & 89.3 & 98.7 & 96.0 & 90.8 \\
\hline & \multicolumn{10}{|c|}{ Group B (n=19) Effusions with ADA>45 u/l; CRP>50 mg/l and/or \%PN >90 } \\
\hline CEA & - & 36.8 & 100.0 & - & 36.8 & 8.3 & 35.3 & 85.7 & 50.0 & 36.8 \\
\hline CA15-3 & 33.3 & 46.7 & 100.0 & 100.0 & 57.9 & 16.7 & 41.2 & 100.0 & 100.0 & 47.4 \\
\hline CA72-4 & 8.3 & 38.9 & 100.0 & 100.0 & 42.1 & 33.3 & 46.7 & 100.0 & 100.0 & 57.9 \\
\hline CA19-9 & - & 36.8 & 100.0 & - & 36.8 & 8.3 & 26.7 & 57.1 & 25.0 & 26.3 \\
\hline CEA+CA15-3 +CA72-4 & 41.7 & 50.0 & 100.0 & 100.0 & 63.2 & 58.3 & 87.7 & 85.7 & 87.5 & 68.4 \\
\hline All TM & 41.7 & 50.0 & 100.0 & 100.0 & 63.2 & 58.3 & 44.4 & 57.1 & 70.0 & 57.9 \\
\hline
\end{tabular}

Sen: Sensibility; Esp: specificity; NPV: negative predictive value; PPV: positive predictive value; Acc: accuracy; \%PN: \%polymorphonuclear cells; CEA: carcinoembryonic antigen CA15-3: cancer antigen 15-3; CA19-9: cancer antigen 19-9; CA72-4: cancer antigen 72-4. †CEA $3340 \mu \mathrm{g} / 1$; CA15-3 71 ku/l; CA72-4 $174 \mathrm{ku} / \mathrm{l}$; CA19-9 $14141 \mathrm{ku} / \mathrm{l}$. $\$ \mathrm{~F} / \mathrm{S}>1: 2$ and at least one of these CEA $>5 \mu \mathrm{g} / 1, \mathrm{CA} 15-3>30 \mathrm{ku} / 1, \mathrm{CA} 72-4>6.9 \mathrm{ku} / \mathrm{l}$ and CA19-9>37 ku/l.

Figure 2 shows the algorism for the interpretation tumor markers in ascitic fluids. In patients with positive ADA, CRP or $\% \mathrm{PN}$ the negative predictive value of the TM was very low, due to the high prevalence $(68 \%)$ of neoplastic ascites in this group. Additionally, in the group with negative ADA, $\mathrm{CRP}$ and $\% \mathrm{PN}$ the prevalence was $43.7 \%$.

\section{Discussion}

This study assessed two strategies for evaluating tumor markers in ascites. Our results are in agreement with previous studies that have used the strategy of the $\mathrm{F} / \mathrm{S}$ ratio (19-21), showing better sensitivity values $(75.7 \%)$ compared to the strategy of a single measurement in fluid with a high cut-off point. For the whole group of patients analyzed, the specificity obtained was $95.2 \%$. In group A, sensitivity rose to $81.4 \%$ and specificity to $98.7 \%$. The rates did not reach the level of $100 \%$ specificity obtained in previous studies (19-20) due to a false positive in CA19-9.

For all effusions in group A the combination of CEA, CA15-3 and CA72-4 showed the maximum specificity $(100 \%)$ with a sensitivity of $79.7 \%$ and in patients with negative cytology from group A the sensitivity of three TMs was $69.7 \%$ at a specificity of $100 \%$. On the other hand, the tumor marker that appeared most frequently as a false positive was CA19-9 in group B (3 out of 7 of patients with benign disease). With regard to the data obtained with the cut-off strategy, the values required for CA19-9 and CEA with the single determination were higher compared to the figures reported by other authors $(6,9,23)$. This was due to the values of one paramalignant effusion, which showed concentrations in serum of $3631 \mathrm{mg} / 1,1161 \mathrm{ku} / 1$ and 89896 $\mathrm{ku} / 1$ for CEA, CA72-4 and CA19-9 respectively and concentrations in peritoneal fluid lower compared to that of the serum $(3230 \mathrm{ng} / \mathrm{ml}, 166 \mathrm{ku} / 1$ and $12884 \mathrm{ku} / 1$ for CEA, CA72-4 and CA19-9 respectively).

It should be noted that most false positives correspond only to CA19-9 (5\% in the patient group as a whole, and $2 \%$ in group A). Three out of seven patients with benign diseases in group B were false positives. One of them, a patient with pancreatitis, has a CA19-9 concentration in fluid of 6370 $\mathrm{ku} / \mathrm{l}$. In a previous study (19) we found a similar value, 7700 $\mathrm{ku} / \mathrm{l}$, in a patient with peritonitis of biliary origin. Indeed, many organs of the abdominal cavity are rich in CA19-9, and inflammation or necrosis may release this marker in large concentrations in the peritoneal fluid. These data suggest that false positives to this marker may be obtained even if high cut-off values are used.

Using the cut-off values obtained by our group in pleural effusions (20), which are similar to those described by Lui 


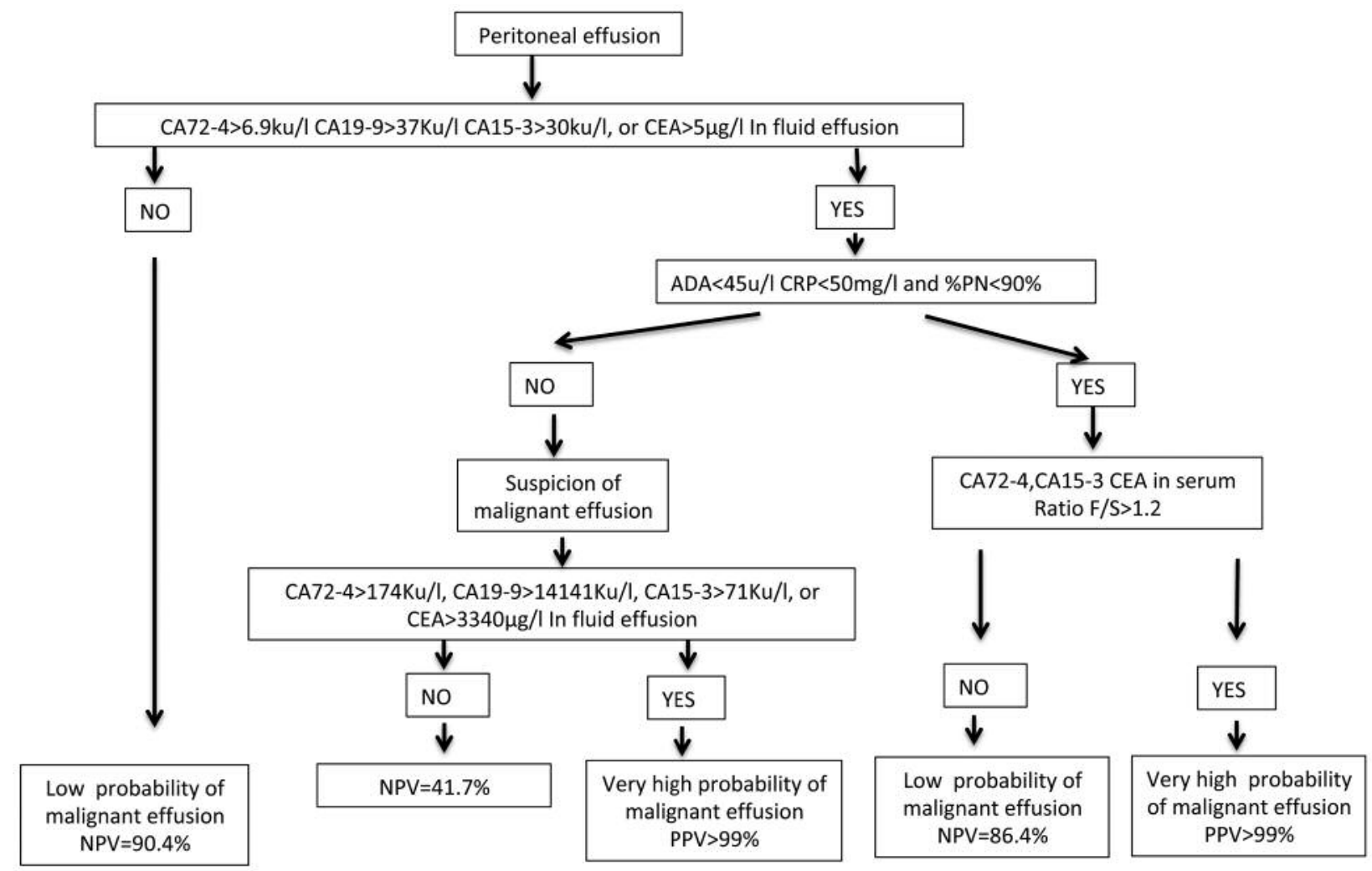

Figure 2. Algorithm for the interpretation of tumor markers in peritoneal fluid. ADA: Adenosine deaminase; CA15-3: cancer antigen 15-3; CA199: cancer antigen 19-9; CA72-4: cancer antigen 72-4. CEA: carcinoembryonic antigen; CRP: C reactive protein; F/S: fluid serum ratio; NPV: negative predictive value; PPV: positive predictive value.

et al. (9) in peritoneal fluid (CEA:60 $\mu \mathrm{g} / 1$, CA19-9:209 ku/1, CA72-4:21 ku/1 and CA15-3:80 ku/l), we obtained sensitivities of $73 \%$ for the whole group and $66.7 \%$ in patients with negative cytology, but with lower specificities (94\% and 94.7\%); therefore, these results were not better compared to those obtained with the ratio strategy.

There was a notable difference between pleural and ascitic effusions in group B, the prevalence of malignant effusions in pleural $(20,23)$ described previously was lower than we found in the present study for peritoneal effusions, since ascitic effusions were more likely to be malignant. Higher concentrations of CRP have been described in peritonitis (15, 16) but also in malignant ascites $(25,26)$. Some ovarian, pancreatic and colonic cancer may have an important inflammatory component. This group may also include lymphomas, which can release ADA in a similar way to pleural effusions (18). In fact, in that study all lymphomas were included in this group. Nevertheless, classifying the effusions according to ADA, CRP and \%PN allowed us to use the best strategy for obtaining higher sensitivity, specificity and diagnostic accuracy.
In this study, more than $50 \%$ of patients with malignant ascites have negative cytology. In these, as yet, undiagnosed patients, more evidence is required to guide the choice of more invasive procedures, such as laparoscopy in order to establish the diagnosis. In this regard, the study of biomarkers in fluid and serum allows identification of $70 \%$ of patients with malignant ascites and negative cytology and has a positive predictive value greater than $99 \%$ in 24 hours, allowing faster assignment to invasive procedures and thus improving efficiency. In summary, patients with a previous diagnosis of neoplasia and the appearance of ascites with negative cytology and a positive $\mathrm{F} / \mathrm{S}$ ratio for tumor markers can be considered to present disease progression. Similarly, the presence of ascites and positive tumor markers but negative cytology in newly diagnosed localized tumors may indicate peritoneal metastasis. These and the other practical considerations raised by our data should be addressed in case by case team discussions.

The main limitation of this study is the fact that it was conducted at a single center. Multicenter studies are now needed to validate clinical data and to establish whether they may also be applicable to other measurement systems. 
We can conclude that to obtain the maximum diagnostic yield from the measurement of CA72-4, CA15-3 and CEA in peritoneal effusions, we should determination markers in fluid and serum with a low cut-off point simultaneously in patients who are unlikely to present increases in TM due to benign disease (i.e., with ADA, CRP and \% PN below the discriminant values).

\section{Conflicts of Interest}

The Authors declare that they have no conflicts of interests regarding this study.

\section{Authors' Contributions}

Conception and design was done by JT, RM. Analysis and interpretation was done by JT, JM, AA, MS, CF, JF, CG-F. Histological examination was performed by FS. EE-V, RP, JA, SC, EC, MD, JT-U, CB, FV, PS, DR, MB, and JO acquired the data. All authors were involved with critical revisions, as well as read and approved the final manuscript.

\section{Acknowledgements}

The Authors also thank Michael Maudsley for help with the translation and edition of the manuscript.

\section{References}

1 Oey RC, van Buuren HR and de Man RA: The diagnostic work-up in patients with ascites: current guidelines and future prospects. Neth J Med 74(8): 330-335, 2016. PMID: 27762220

2 Motherby H, Nadjari B, Friegel P, Kohaus J, Ramp U and Böcking A: Diagnostic accuracy of effusion cytology. Diagn Cytopathol 20: 350-357, 1999. PMID: 10352907. DOI: 10.1002/(sici)1097-0339(199906)20:6<350::aid-dc5>3.0.co;2-7

3 Shi HZ, Liang QL, Jiang J, Qin XJ and Yang HB: Diagnostic value of carcinoembryonic antigen in malignant pleural effusion: a meta-analysis. Respirology 13(4): 518-527, 2008. PMID: 18422869. DOI: $10.1111 / j .1440-1843.2008 .01291 . x$

4 Liang QL, Shi HZ, Qin XJ, Liang XD, Jiang J and Yang HB: Diagnostic accuracy of tumour markers for malignant pleural effusion: a meta-analysis. Thorax 63(1): 35-41, 2008. PMID: 17573438. DOI: 10.1136/thx.2007.077958

5 Ahadi M, Tehranian S, Memar B, Vossoughinia H, Salari M, Eskandari E, Farzanehfar M and Sadeghi R: Diagnostic value of carcinoembryonic antigen in malignancy-related ascites: systematic review and meta-analysis. Acta Gastroenterol Belg 77(4): 418-424, 2014. PMID: 25682632.

6 Zhu FL, Ling AS, Wei Q, Ma J and Lu G: Tumor markers in serum and ascites in the diagnosis of benign and malignant ascites. Asian Pac J Cancer Prev 16(2): 719-722, 2015. PMID: 25684514. DOI: 10.7314/apjcp.2015.16.2.719

7 Gulyás M, Kaposi AD, Elek G, Szollár LG and Hjerpe A: Value of carcinoembryonic antigen (CEA) and cholesterol assays of ascitic fluid in cases of inconclusive cytology. J Clin Pathol 54(11): 831-835, 2015. PMID: 11684715. DOI: 10.1136/jcp.54.11.831
8 Kaleta EJ, Tolan NV, Ness KA, O'Kane D and AlgecirasSchimnich A: CEA, AFP and CA 19-9 analysis in peritoneal fluid to differentiate causes of ascites formation. Clin Biochem 46(9): 814-818, 2013. PMID: 23454392. DOI: 10.1016/j.clinbiochem. 2013.02.010

9 Liu F, Kong X, Dou Q, Ye J, Xu D, Shang H, Xu K and Song Y: Evaluation of tumor markers for the differential diagnosis of benign and malignant ascites. Ann Hepatol 13(3): 357-363, 2014. PMID: 24756011.

10 Han N, Sun X, Qin C, Hassan Bakari K, Wu Z, Zhang Y and Lan X: Value of (18)F-FDG PET/CT combined with tumor markers in the evaluation of ascites. AJR Am J Roentgenol 210(5): 1155-1163, 2018. PMID: 29629798. DOI: 10.2214/ AJR.17.18733

11 Slev PR, Rawlins ML and Roberts WL: Performance characteristics of seven automated CA 15-3 assays. Am J Clin Pathol 125(5): 752-757, 2006. PMID: 16707378. DOI: 10.1309/G6X6-PR75-26FA-KV0E

12 Mansour M, Linden ER, Colby S, Posner G and Marsh F Jr: Elevation of carcinoembryonic antigen and CA-125 in a patient with multivisceral tuberculosis. J Natl Med Assoc 89(2): 142143, 1997. PMID: 9046768.

13 Wu SS, Lin OS, Chen YY, Hwang KL, Soon MS and Keeffe EB: Ascitic fluid carcinoembryonic antigen and alkaline phosphatase levels for the differentiation of primary from secondary bacterial peritonitis with intestinal perforation. J Hepatol 34(2): 215-221, 2001. PMID: 11281549. DOI: 10.1016/s0168-8278(00)00039-8

14 Tao L, Ning HJ, Nie HM, Guo XY, Qin SY and Jiang HX: Diagnostic value of adenosine deaminase in ascites for tuberculosis ascites: a meta-analysis. Diagn Microbiol Infect Dis 79(1): 102-107, 2014. PMID: 24629577. DOI: 10.1016/j.diagmicrobio.2013.12.010

15 Yildirim B, Sari R and Isci N: Patients with spontaneous bacterial peritonitis, and malignant and cirrhotic ascites. J Natl Med Assoc 97(2): 276-280, 2005. PMID: 15712792.

16 Mousa N, Besheer T, Abdel-Razik A, Hamed M, Deiab AG, Sheta $\mathrm{T}$ and Eldars W: Can combined blood neutrophil to lymphocyte ratio and $\mathrm{C}$-reactive protein be used for diagnosis of spontaneous bacterial peritonitis? Br J Biomed Sci 75(2): 71-75, 2018. PMID: 29452544. DOI: 10.1080/09674845.2017.1396706

17 Lutz P, Goeser F, Kaczmarek DJ, Schlabe S, Nischalke HD, Nattermann J, Hoerauf A, Strassburg CP and Spengler U: Relative ascites polymorphonuclear cell count indicates bacterascites and risk of spontaneous bacterial peritonitis. Dig Dis Sci 62(9): 2558-2568, 2017. PMID: 28597106. DOI: 10.1007/s10620-017-4637-4

18 Trapé J, Filella X, Alsina-Donadeu M, Juan-Pereira L, BoschFerrer Á and Rigo-Bonnin R: Oncology Section of the Catalan Association of Clinical Laboratory Science. Increased plasma concentrations of tumour markers in the absence of neoplasia. Clin Chem Lab Med 49(10): 1605-1620, 2011. PMID: 21892908. DOI: 10.1515/CCLM.2011.694

19 Trapé J, Molina R, Sant F, Montesinos J, Arnau A, Franquesa J, Blavia R, Martín E, Marquilles E, Perich D, Pérez C, Roca JM, Doménech M, López J and Badal JM: Diagnostic accuracy of tumour markers in serous effusions: a validation study. Tumour Biol 33(5): 1661-1668. PMID: 22678976. DOI: 10.1007/s13277012-0422-3

20 Trapé J, Sant F, Franquesa J, Montesinos J, Arnau A, Sala M, Bernadich O, Martín E, Perich D, Pérez C, Lopez J, Ros S, 
Esteve E, Pérez R, Aligué J, Gurt G, Catot S, Domenech M, Bosch J, Badal JM, Bonet M, Molina R and Ordeig J: Evaluation of two strategies for the interpretation of tumour markers in pleural effusions. Respir Res 18(1): 103, 2017. PMID: 28545517. DOI: 10.1186/s12931-017-0582-1

21 Trapé J, Molina R and Sant F: Clinical evaluation of the simultaneous determination of tumor markers in fluid and serum and their ratio in the differential diagnosis of serous effusions. Tumour Biol 25(5-6): 276-281, 2004. PMID: 15627892. DOI: $10.1159 / 000081392$

22 Trapé J, Gurt G, Franquesa J, Montesinos J, Arnau A, Sala M, Sant F, Casado E, Ordeig JM, Bergos C, Vida F, Sort P, Isava Á, González $\mathrm{M}$ and Molina R: Diagnostic accuracy of tumor markers CYFRA21-1 and CA125 in the differential diagnosis of ascites. Anticancer Res 35(10): 5655-5660, 2015. PMID: 26408739

23 Trapé J, Sant F, Montesinos J, Arnau A, Sala M, Bernadich O, Martín E, Perich D, Lopez J, Ros S, Esteve-Valverde E, Pérez R, González-Fernández C, Aligue J, Catot S, Domenech M, Ruiz $\mathrm{D}$, Bonet M, Molina R and Ordeig J: Diagnostic accuracy of CYFRA21-1 in the differential diagnosis of pleural effusions. Anticancer Res 39(9): 5071-5076, 2019. PMID: 31519617. DOI: 10.21873/anticanres. 13700
24 Chen SJ, Wang SS, Lu CW, Chao Y, Lee FY, Lee SD, Wu SL, Cherng KL, and Lo KJ: Clinical value of tumour markers and serum-ascites albumin gradient in the diagnosis of malignancyrelated ascites. J Gastroenterol Hepatol 9(4): 396-400, 1994. PMID: 7948823. DOI: 10.1111/j.1440-1746.1994.tb01262.x

25 Yuksel I, Karaahmet F, Coskun Y, Kilıncalp S, Hamamci M, Akinci H, Ustun Y, Simsek Z, Erarslan E and Coban S: Significance of serum and ascitic fluid C-reactive protein in differential diagnosis of benign and malignant ascites. Dig Dis Sci 59(10): 2588-2593, 2014. PMID: 24838501. DOI: 10.1007/s10620-014-3205-4

26 Abdel-Razik A, Mousa N, Elalfy H, Sheta TF, Awad M, Abdelsalam M, Elhelaly R, Elzehery R, Gouda NS and Eldars $\mathrm{W}$ : A novel combination of $\mathrm{C}$-reactive protein and vascular endothelial growth factor in differential diagnosis of ascites. J Gastrointest Cancer 48(1): 50-57, 2017. PMID: 27614744. DOI: $10.1007 / \mathrm{s} 12029-016-9873-\mathrm{x}$

Received November 7, 2019

Revised November 19, 2019

Accepted November 26, 2019 